\title{
Multidetector-row computed tomography in the preoperative diagnosis of intestinal complications caused by clinically unsuspected ingested dietary foreign bodies: a case series emphasizing the use of volume rendering techniques*
}

Tomografia computadorizada com multidetectores no diagnóstico pré-operatório das complicações intestinais causadas pela ingestão de corpos estranhos da dieta sem suspeita clínica: série de casos enfatizando o uso de técnicas de renderização volumétrica

\author{
Augusto César Vieira Teixeira ${ }^{1}$, Ulysses dos Santos Torres ${ }^{1}$, Carlos Eduardo Garcia Westin ${ }^{2}$, \\ Eduardo Portela de Oliveira ${ }^{1}$, Fabiana Gual ${ }^{1}$, Luciana Vargas Cardoso ${ }^{3}$, Tufik Bauab Jr. ${ }^{4}$
}

\begin{abstract}
Objective: The present study was aimed at describing a case series where a preoperative diagnosis of intestinal complications secondary to accidentally ingested dietary foreign bodies was made by multidetector-row computed tomography (MDCT), with emphasis on complementary findings yielded by volume rendering techniques (VRT) and curved multiplanar reconstructions (MPR). Materials and Methods: The authors retrospectively assessed five patients with surgically confirmed intestinal complications (perforation and/or obstruction) secondary to unsuspected ingested dietary foreign bodies, consecutively assisted in their institution between 2010 and 2012. Demographic, clinical, laboratory and radiological data were analyzed. VRT and curved MPR were subsequently performed. Results: Preoperative diagnosis of intestinal complications was originally performed in all cases. In one case the presence of a foreign body was not initially identified as the causal factor, and the use of complementary techniques facilitated its retrospective identification. In all cases these tools allowed a better depiction of the entire foreign bodies on a single image section, contributing to the assessment of their morphology. Conclusion: Although the use of complementary techniques has not had a direct impact on diagnostic performance in most cases of this series, they may provide a better depiction of foreign bodies' morphology on a single image section.
\end{abstract}

Keywords: Foreign bodies; Intestinal perforation; Intestinal obstruction; Multidetector computed tomography.

Resumo Objetivo: Descrever uma série de casos em que o diagnóstico pré-operatório de complicações intestinais secundárias à ingestão acidental de corpos estranhos da dieta foi realizado por tomografia computadorizada com multidetectores (TCMD), enfatizando-se os achados complementares de técnicas de renderização volumétrica (VRT) e reconstruções curvas multiplanares (MPR). Materiais e Métodos: Foram analisados, retrospectivamente, cinco pacientes com complicações intestinais (perfuração e/ou obstrução) secundárias à ingestão insuspeita de corpos estranhos da dieta confirmadas cirurgicamente, consecutivamente atendidos em nosso serviço entre 2010 e 2012. Foram analisados dados demográficos, clínicos, laboratoriais e radiológicos. VRT e MPR foram aplicadas subsequentemente. Resultados: Em todos os casos o diagnóstico pré-operatório de complicações intestinais foi realizado. Em um caso um corpo estranho não foi identificado como fator causal, e o uso de técnicas complementares facilitou sua identificação retrospectiva. Em todos os casos essas técnicas favoreceram melhor representação de toda a extensão dos corpos estranhos em um único corte, contribuindo para a avaliação da morfologia desses corpos estranhos. Conclusão: Embora a aplicação de técnicas complementares não tenha determinado impacto direto sobre o diagnóstico na maioria dos casos desta série, elas podem propiciar uma melhor representação da morfologia do corpo estranho em um único corte.

Unitermos: Corpos estranhos; Perfuração intestinal; Obstrução intestinal; Tomografia computadorizada multidetectores.

Teixeira ACV, Torres US, Westin CEG, Oliveira EP, Gual F, Cardoso LV, Bauab Jr T. Multidetector-row computed tomography in the preoperative diagnosis of intestinal complications caused by clinically unsuspected ingested dietary foreign bodies: a case series emphasizing the use of volume rendering techniques. Radiol Bras. 2013 Nov/Dez;46(6):346-350.

* Study developed in the Unit of Radiology and Imaging Diagnosis at Hospital de Base - Faculdade de Medicina de São José do Rio Preto (Famerp), São José do Rio Preto, SP, Brazil.

1. MDs, Residents in Radiology and Imaging Diagnosis, Hospital de Base - Faculdade de Medicina de São José do Rio Preto (Famerp), São José do Rio Preto, SP, Brazil.

2. MD, Resident in General Surgery at Hospital de Base -
Faculdade de Medicina de São José do Rio Preto (Famerp), São José do Rio Preto, SP, Brazil.

3. MD, Radiologist, Head of the Sector of Comput Tomography, Unit of Radiology at Hospital de Base - Faculdade de Medicina de São José do Rio Preto (Famerp), São José do Rio Preto, SP, Brazil.

4. PhD, MD, Radiologist, Unit of Radiology, Hospital de Base
- Faculdade de Medicina de São José do Rio Preto (Famerp), São José do Rio Preto, SP, Brazil.

Mailing Address: Dr. Ulysses dos Santos Torres. Hospital de Base - Serviço de Radiologia e Diagnóstico por Imagem. Avenida Brigadeiro Faria Lima, 5544, Vila São Pedro. São José do Rio Preto, SP, Brazil, 15090-000. E-mail: usantor@yahoo.com.br. 2013 


\section{INTRODUCTION}

Accidental ingestion of foreign bodies (FB) is relatively common in the general population. Although most ingested FB pass uneventfully through the gastrointestinal (GI) tract within one week ${ }^{(\mathbf{1})}$, in a small proportion $(<1 \%)$ of cases complications such as perforations are observed ${ }^{(1-4)}$, especially when involving long, hard, or sharp objects $^{(4)}$, which are precisely the features of dietary fish and chicken bones. In fact, ingested alimentary bone fragments have been implicated in up to $85 \%$ of GI tract perforations in some series ${ }^{(3)}$, being fish bones not only the most commonly ingested FB, but also the most common cause of FB-related perforations ${ }^{(\mathbf{1})}$. Considering that GI tract complications may lead to severe clinical outcomes or even death, and as clinical and even preoperative diagnoses are not frequently performed ${ }^{(\mathbf{1 , 5})}$, radiologists may play an important role in first suggesting such diagnosis, usually in the setting of a computed tomography (CT) scan ordered to assess a patient presenting with acute abdomen ${ }^{(5)}$.

The role of multidetector-row CT (MDCT) in the preoperative diagnosis of GI tract complications secondary to ingestion of FB has seldom been described in the literature $^{(\mathbf{1 , 4 - 8})}$. Notwithstanding, MDCT allows excellent anatomical detail of the intestinal wall, also detecting indirect signs of bowel perforation, such as surrounding fat stranding and localized pneumoperitoneum $^{(5)}$. Additionally, by means of high resolution, thin-collimated submillimiter isotropic imaging obtained with short acquisition times, and with the capability of superb multiplanar reconstructions afforded by larger scan volumes, a whole bowel assessment can be made with the identification of hyperdense FB regardless its spatial orientation ${ }^{(7)}$.

In many clinical situations, however, axial MDCT images solely may be insufficient to reach an appropriate diagnosis ${ }^{(9)}$. Such assertion is applicable particularly as the frequently very subtle findings of FBrelated GI complications are considered. Although the paramount importance of curved multiplanar reconstructions (curved MPR) and MDCT volume rendering techniques (VRT) such as maximum intensity projection (MIP) and volume rendering (VR) is well documented in many clinical contexts, the full potential of such techniques is not usually employed by many radiologists $^{(\mathbf{9})}$. In fact, the use of MDCT VRT to assess intestinal perforation or obstruction caused by dietary FB, for example, has received little attention in the literature $^{(6,8)}$ and, to the best of the authors' knowledge, this is the first series illustrating the findings yielded by these techniques in such a context.

\section{MATERIALS AND METHODS}

The authors reviewed the medical records of all patients admitted to their institution between May 2010 and October 2012 who had a confirmed surgical diagnosis of intestinal complications (perforation and/or obstruction) caused by dietary foreign bodies. Only the patients who underwent a preoperative CT scan and with complications involving any location between duodenum and rectum were included. Eight patients underwent emergency surgical procedures due to GI tract complications secondary to ingested alimentary foreign bodies. All the patients were unaware of having ingested an FB preoperatively. Three patients did not undergo a preoperative CT scan and were then excluded. Informed consent was waived by the Institutional Review Board.

The five patients' case notes, including clinical and surgical data were retrospectively reviewed. The following parameters were studied: clinical history, laboratory tests, involved site and type of FB. In all these five cases plain radiography and abdominal ultrasonography were performed without a conclusive diagnosis. Based on conventional MDCT findings, the authors could identify the cases where a conclusive preoperative diagnosis was originally reached, further conducting a retrospective imaging analysis of the corresponding CT scans, which were consensually reviewed and interpreted by a radiologist (14-year experience) and a resident in radiology, who were blinded for the type of complication and involved site but not for the history of FB-related intestinal complications. Finally, the authors employed additional VRT (MIP and VR in all cases) and curved
MPR (as necessary in three cases) and compared the resulting images with the previous conventional ones.

All patients underwent CT scans after intravenous contrast agent bolus injection at a rate of $3-5 \mathrm{ml} / \mathrm{s}$. The CT scans were performed in a Philips 16 Brilliance CT 16slice scanner (Philips Medical Systems; Best, The Netherlands) using the following parameters: 2 mm collimation, $120 \mathrm{kVp}$ and 260-295 mAs. MIP reformations were obtained with 8-mm thick slices. All the scans were performed without the use of oral contrast media. Both curved multiplanar reformations and 3D reconstructions (MIP and 3D VR) were performed on a dedicated ViewForum workstation (Philips Medical Systems; Best, The Netherlands).

\section{RESULTS}

Demographic data, clinical features, and MDCT findings are summarized on Table 1. The five patients' median age was 67.6 years (age range, 59-85 years). There were three men $(65,67$ and 85 years) and two women (59 and 62 years). All patients presented to the emergency department with acute abdominal symptoms for 3.8 days on average (range, 2-8 days). Two patients presented with diffuse abdominal pain and three patients had a more localized abdominal pain (right lower quadrant in one case and hypogastric area in two cases). Bowel obstruction symptoms were present in three patients at admission, and such obstruction was further confirmed by CT findings and surgery in these three cases. Laboratory tests results were altered in all the patients, with white cell count at 7,450 to 14,320 and C-reactive protein at 10.0-29.2 mg (reference value $0-0.5 \mathrm{mg}$ ) at admission. At plain abdominal radiography, three patients showed hydroaeric levels, but pneumoperitoneum was not identified in any case. All the patients underwent laparotomy for management of intestinal complications; the involved site was the ileum in two cases; sigmoid colon in two cases; and the rectosigmoid junction and high rectum in one case.

The FB were fish bones in three patients and chicken bones in two patients. According to the original $\mathrm{CT}$ reports, intestinal complications were correctly identified in all five cases, but the causes of these com- 
Table 1 Demographic and clinical data with CT findings in five cases of intestinal complications secondary to clinically unsuspected ingested dietary foreign bodies.

\begin{tabular}{|c|c|c|c|c|c|}
\hline \multicolumn{6}{|c|}{ Demographic and clinical data } \\
\hline Patient & 1 & 2 & 3 & 4 & 5 \\
\hline Sex/age (years) & $\mathrm{F} / 62$ & $\mathrm{M} / 85$ & M/65 & $\mathrm{M} / 67$ & $\mathrm{~F} / 59$ \\
\hline $\begin{array}{l}\text { Location of abdominal pain/ } \\
\text { duration (days) }\end{array}$ & Diffuse/2 & Hypogastric area/4 & Diffuse/3 & Right lower/2 & Hypogastric area/8 \\
\hline Bowel obstruction symptoms & - & + & + & + & - \\
\hline White cell count $\left(/ \mathrm{mm}^{3}\right)$ & 7,450 & 12,720 & 10,800 & 14,320 & 8,880 \\
\hline C-reactive protein (mg) & 10.0 & 19.5 & 11.4 & 29.2 & 11.5 \\
\hline Site of complication & Ileum & Sigmoid colon & Sigmoid colon & Ileum & $\begin{array}{l}\text { Rectosigmoid junction and } \\
\text { high rectum }\end{array}$ \\
\hline Nature of complication & Perforation & Obstruction & Perforation and obstruction & Perforation and obstruction & Perforation \\
\hline Nature of foreign body & Fish bone & Chicken bone & Fish bone & Fish bone & Chicken bone \\
\hline \multicolumn{6}{|c|}{ Plain radiography findings } \\
\hline Hydroaeric levels & - & + & + & + & - \\
\hline Pneumoperitoneum & - & - & - & - & - \\
\hline \multicolumn{6}{|c|}{ MDCT findings } \\
\hline Mural thickening & + & + & + & - & - \\
\hline Localized pneumoperitoneum & + & - & + & + & - \\
\hline Surrounding fat stranding & + & + & + & + & - \\
\hline Bowel obstruction signs & - & + & + & + & - \\
\hline
\end{tabular}

F, female; M, male.

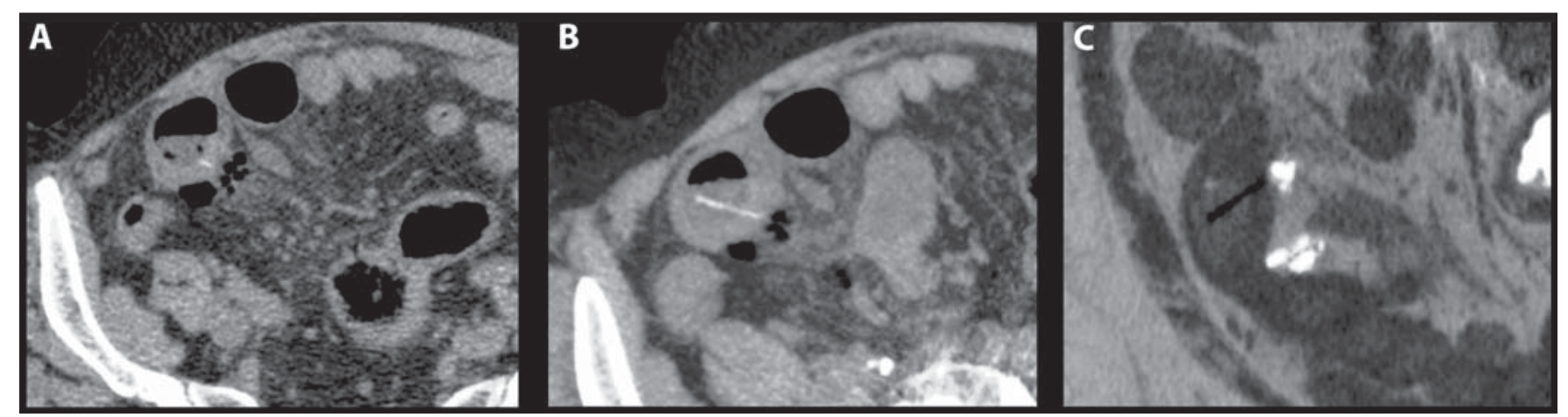

Figure 1. Patient 1. Non-contrast-enhanced axial CT image (A) shows a small linear hyperdensity within a thickened ileal bowel in association with extraluminal air and minor infiltration of surrounding fat (this FB was originally missed at the first analysis); axial (B) and inverted grayscale coronal oblique (C) reformations with MIP allow the depiction of the whole linear FB (a fish bone) clearly transfixing the ileal wall.

plications were originally seen in four of them, as in one case of ileal perforation by fish bone (Figure 1) the long axis of the FB was obliquely positioned in relation to the intestinal wall, which has made its depiction more difficult; in such a case, therefore, the use of VRT and curved MPR retrospectively allowed an easier and better identification of the FB. All cases were correctly identified regarding type and site of complication in the reanalysis, and mural thickening of an intestinal segment (3/5 patients) with extraluminal gas (localized pneumoperitoneum) (3/5 patients), and surrounding infiltrated fat (4/5 patients) were the most common CT signs. Although not critical for the diagnosis in most cases, the retrospective application of VRT techniques allowed the depiction of the entire FB on a single image section (Figures 1 and 3 ) or the depiction of two consecutive but distinctly oriented FB with the utilization of curved MPR in association with MIP (Figure 2).

\section{DISCUSSION}

Complications secondary to ingested FB may occur anywhere in the gastrointestinal tract, from mouth to anus, although the segments more commonly affected are those less fixed and with angulations, such as the ileum, ileocecal and rectosigmoid regions ${ }^{(4,5,7)}$. Unlike intentional cases of FB ingestion that usually occurs with prisoners and individuals attempting suicide, most cases are accidental, occurring in children and elderly people, individuals with dentures, psychiatric patients and alcohol or drug abusers ${ }^{(\mathbf{1 , 5})}$. Dietary bone fragments, particularly, represent a challenge in the diagnosis of FB perforation, as these objects are swallowed numerous times, accidentally ingested and forgotten ${ }^{(\mathbf{1})}$. Therefore, because of the inability to obtain a 
history of FB ingestion, the consequential low degree of clinical suspicion, and also because of the nonspecificity of clinical presentation $^{(\mathbf{1 , 5})}$, perforations secondary to dietary FB are extremely difficult to diagnose $^{(\mathbf{1})}$. In this sense, images should be assessed with a high level of suspicion ${ }^{(\mathbf{5}, 7)}$, as an accurate preoperative diagnosis may guide the appropriate treatment, either surgical or clinical ${ }^{(7)}$. Nonetheless, the radiological diagnosis is also often difficult, and in many cases the correct diagnosis is only made during laparotomy performed in the setting of acute abdomen ${ }^{(7)}$.

Plain radiography plays a very limited role in the diagnosis of gastrointestinal complications secondary to dietary FB. Although most chicken bones and some fish bones are usually radiodense structures, their depiction may be impaired in obese patients or in technically poorly performed scans, for example ${ }^{(\mathbf{1})}$. Furthermore,
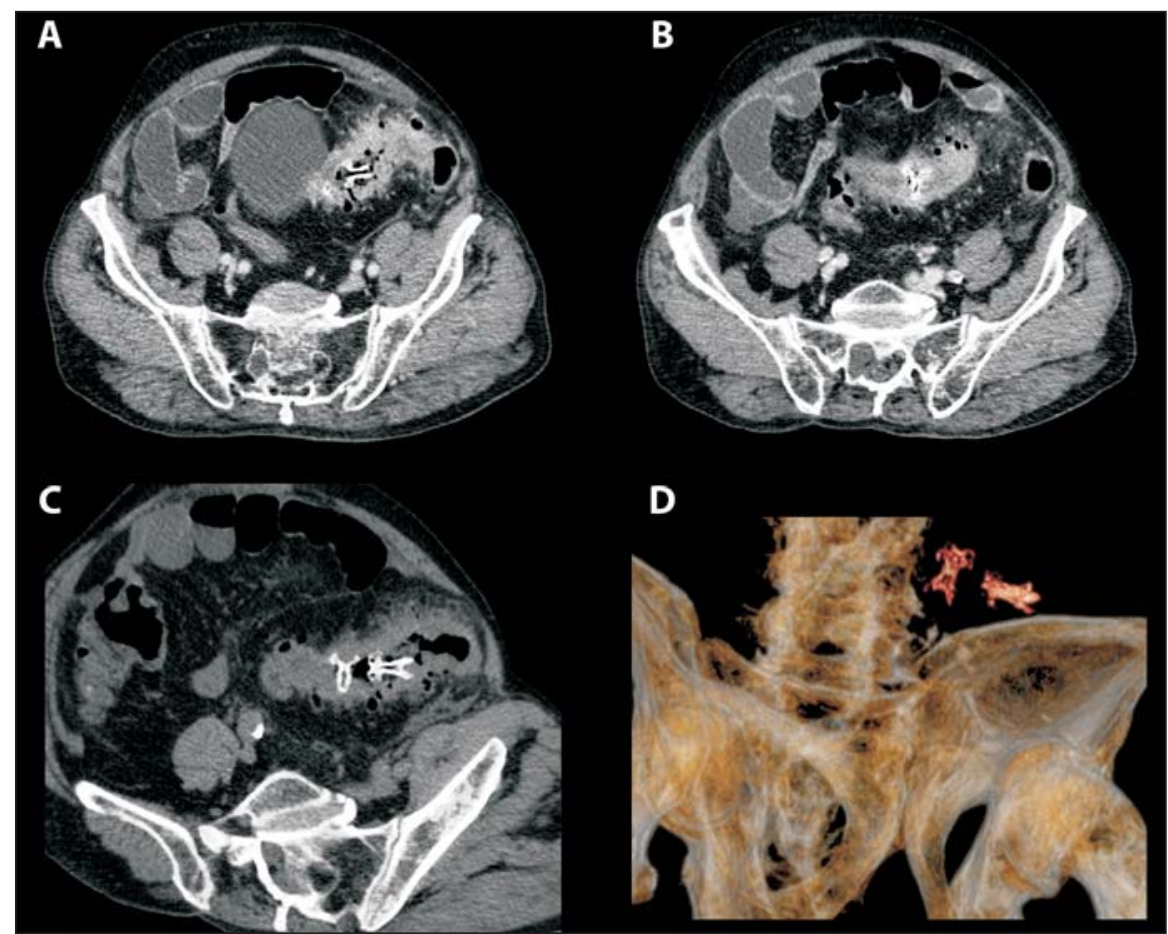

Figure 2. Patient 2. Axial (A,B) contrast-enhanced CT scan at two different levels depicts two intraluminal hyperdense FB (chicken bones) in the sigmoid colon, which demonstrates mural thickening with marked enhancement and discreet surrounding fat stranding; note the findings of sigmoid diverticula, with no evidence of localized pneumoperitoneum. Coronal oblique $(\mathbf{C})$ reformation of the non-contrast-enhanced phase with MIP depicts the two FBs on a single image section, confirming the absence of sigmoid wall transfixation and better revealing the immediately distal obstruction induced by the inflammatory process. Complementarily, VR image (D) shows the morphology of FB. free pneumoperitoneum, which might be an expected finding leading to this clinical suspicion, is actually rare as the perforation is caused by a gradual impaction of the FB against the wall and the site of perforation is usually covered by fibrin ${ }^{(1,5)}$. Ultrasonography presents the advantage of identifying high-reflective FB (even those non-radiodense, such as toothpicks) associated with a wide availability, low cost, lack of ionizing radiation, and the possibility of an approach focused on a painful area combining palpation and real time imaging. On the other hand, it is operator-dependent and its accuracy is also influenced by patient's body habitus and site of perforation ${ }^{(7)}$.

In the literature, the role of MDCT in the setting of FB-related complications has been described in some case reports and case series $^{(\mathbf{1}, 4-8)}$. Coulier et al. ${ }^{(7)}$ have studied seven cases of ileal perforation caused by dietary FB (four chicken bones and three fish bones) using spiral CT and MDCT. Regional mural thickening, localized pneumoperitoneum, surrounding fat stranding and occlusion/subocclusion signs were the most common CT findings; in all cases a calcified FB was identified, although it was necessary a very careful analysis of all image sections and the use of multiplanar reconstructions. Goh et al. ${ }^{(\mathbf{1})}$ have studied the role of $\mathrm{CT}$ in the preoperative diagnosis of gastrointestinal tract perforations by fish bones in a series of seven patients, finding an initial sensitivity of $71.4 \%$ ( $5 / 7$ patients) in the detection of FB, which increased to $100 \%$ after a retrospective review. The authors have concluded that the lack of observer awareness was the main obstacle to the detection of FB; so, again, a high level

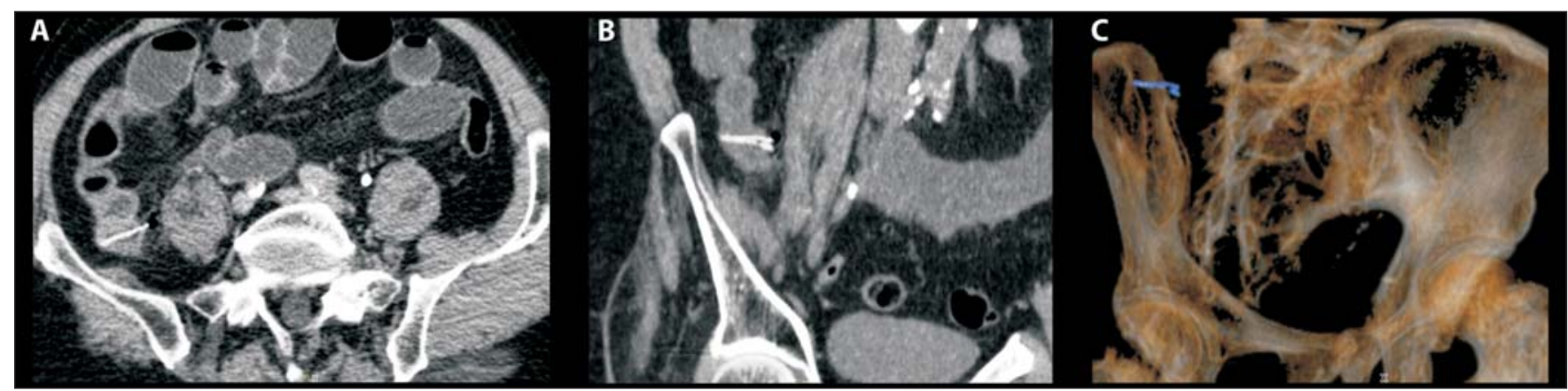

Figure 3. Patient 4. Axial (A) contrast-enhanced CT image shows an intraluminal linear calcified FB (a fish bone) transversely oriented in an ileal bowel and transfixing its wall, associated with minimal surrounding fat stranding and small amount of free pneumoperitoneum. Coronal oblique (B) reformation of the noncontrast-enhanced phase with MIP allows the visualization of the whole FB and a better detailing of its morphology (note the bifurcate ending), which can be further assessed on a VR image (C). 
of suspicion is recommended. In the present series, oral contrast agent was not employed in any case. In fact, the use of positive oral contrast agents should be avoided in patients presenting to the emergency department with undifferentiated abdominal pain, especially considering that FB-related intestinal complications are a potential etiology in this setting and that hyperattenuating oral contrast material may impair the identification of a radiodense $\mathrm{FB}^{(10)}$. In this sense, eliminating routine oral contrast use does not seem to compromise the diagnosis in non-postoperative patients with acute abdominal pain ${ }^{(\mathbf{1 1})}$.

In the present study, the authors have also aimed at illustrating the complementary findings yielded by techniques such as VRT and MPR which in some cases may contribute for the assessment of morphological alterations. This was based on the assumption that as these FB appear as hyperdense structures at CT (although some of them may be only slightly hyperdense or appear as very faint structures, depending on their spatial orientation), techniques such as MIP might enhance them. The MIP technique allows the distinction of hyperdense structures from surrounding soft tissues; its algorithm is based on the principle that to a given volume the pixels with the highest Hounsfield numbers are better represented along the $z$ axis on a single bidimensional image ${ }^{(9)}$. In this sense, MIP can significantly reduce the time required to analyze complex structures such as FB (even those with a non-linear course and in different planes), also allowing a better understanding of their extent (depending on spatial orientation) and morphology ${ }^{(9)}$. After the identification of such structures, curved MPR may be used to follow them spatially along their whole extent. Finally, by creating and displaying from any perspective a 3D visual illustration of CT volumetric data ${ }^{(9)}$, VR may be a complementary mode to depict FB and eas- ily understand its morphology. As in only one case in this series a FB was originally missed on axial sections, the use of VRT and curved MPR at that time would not have had a direct impact on the diagnostic performance in most cases. However, these techniques provided a better depiction of the entire FB on a single image section. Additionally, VR advantage of providing a sensation of three-dimensionality ${ }^{(9)}$ facilitates a rapid, clear and intuitive identification of FB by laypersons, which may be useful for documentation purposes.

Hitherto, the use of VRT for the assessment of FB has been described in isolated case reports. In the early 2000 s, Takada et al. ${ }^{(6)}$ employed 3D-CT to identify a fish bone that appeared only as a hyperdense spot in the center of a large abscess near the sigmoid colon on conventional axial sections, and thus it would not have been recognized as a FB. Three-dimensional CT allowed identifying the FB, to assess its slightly curved morphology and to reach a presumptive preoperative diagnosis of intestinal perforation caused by a fish bone. Recently, Chang et al. ${ }^{(8)}$ used CT colonography to demonstrate a transversely located chicken bone causing incomplete perforation of the distal sigmoid colon, which contributed to the preoperative evaluation and to the choice of a therapeutic approach. To the best of authors' knowledge, this is the first case series addressing the VRT findings of intestinal complications caused by dietary FB.

Limitations of this study include: a) the fact that reviewers were not blinded to the presence of a FB complication in each case during the reanalysis; b) the retrospective nature of the study; and c) the limited study sample, despite the fact that most important studies about CT in the current literature on this subject have limited samples comprising as few as a maximum of seven patients ${ }^{(1,7)}$. Notwithstanding the difficulty in encompassing large samples of such patients in the radiological literature, further larger prospective studies might better statistically define the value of VRT in this setting. Although it has been argued that it is not practical for most institutions to use $3 \mathrm{D}$ reconstruction to assess all patients with acute abdomen $^{(\mathbf{1})}$, it seems reasonable to consider that in some very restricted emergency cases of patients with nonspecific abdominal complaints and unexplained intestinal alterations depicted at CT (e.g., mural thickening, localized pneumoperitoneum, fat stranding), VRT and curved MPR might be useful in the search for an unsuspected dietary FB that may have been overlooked on a first reading.

\section{REFERENCES}

1. Goh BK, Tan YM, Lin SE, et al. CT in the preoperative diagnosis of fish bone perforation of the gastrointestinal tract. AJR Am J Roentgenol. 2006;187:710-14.

2. Pinero Madrona A, Fernández Hernández JA, Carrasco Prats M, et al. Intestinal perforation by foreign bodies. Eur J Surg. 2000;166:307-9.

3. Goh BK, Chow PK, Quah HM, et al. Perforation of the gastrointestinal tract secondary to ingestion of foreign bodies. World J Surg. 2006;30:372-7.

4. Gayer G, Petrovitch I, Jeffrey RB. Foreign objects encountered in the abdominal cavity at $\mathrm{CT}$. Radiographics. 2011;31:409-28.

5. Zissin R, Osadchy A, Gayer G. Abdominal CT findings in small bowel perforation. Br J Radiol. 2009;82:162-71.

6. Takada M, Kashiwagi R, Sakane M, et al. 3D-CT diagnosis for ingested foreign bodies. Am J Emerg Med. 2000;18:192-3.

7. Coulier B, Tancredi MH, Ramboux A. Spiral CT and multidetector-row CT diagnosis of perforation of the small intestine caused by ingested foreign bodies. Eur Radiol. 2004;14:1918-25.

8. Chang KJ, Schechter S, Vrees M, et al. Ingested foreign body in the sigmoid colon: detection and localization by CT colonography. Med Health R I. 2012;95:47-8.

9. Perandini S, Faccioli N, Zaccarella A, et al. The diagnostic contribution of CT volumetric rendering techniques in routine practice. Indian J Radiol Imaging. 2010;20:92-7.

10. Grand DJ, Cloutier DR, Beland MD, et al. Inadvertent ingestion of wire bristles from a grill cleaning brush: radiologic detection of unsuspected foreign bodies. AJR Am J Roentgenol. 2012;198: 836-9.

11. Stoker J, van Randen A, Laméris W, et al. Imaging patients with acute abdominal pain. Radiology. 2009;253:31-46. 